\title{
O diálogo aberto e os desafios para sua implementação - análise a partir da revisão da literatura
}

\author{
Open Dialogue and the Challenges for its Implementation \\ - an analysis based on a review of the literature
}

Luciane Prado Kantorski ${ }^{1}$

Mario Cardano ${ }^{2}$
${ }^{1}$ Faculdade de Enfermagem, Universidade Federal de Pelotas. R. Gomes Carneiro 1, Centro. 96010-610 Pelotas RS Brasil.

kantorski@uol.com.br

2 Dipartimento di Culture, Politica e Società, Università degli Studi di Torino. Torino Piemonte Itália.

\begin{abstract}
The Open Dialogue Method was developed in Finland in order to deal with severe psychotic crises using dialogue and social network inclusion. By means of a review of the literature on the Open Dialogue Method, this article sought to identify the principles and contributions for deinstitutionalization. Method: The PubMed (365), PsycInfo (134), Lilacs (no articles found) databases and 2 books were consulted. Thirty-four publications that fulfilled the requirements of this review were selected. The search was conducted in October 2015. The key words used were: open dialogue, crisis, first psychotic episode, schizophrenia, family therapy, need-adapted approach. Results: There were 3 reviews, 5 theoretical studies, 21 qualitative studies and 5 quantitative studies. Two of them were written in Italian, one in French and thirty-one in English. The authors were from Norway, the United States, Finland, Australia, the United Kingdom, Belgium, Canada and Poland. The publications were grouped for purposes of analysis into the following categories: Open Dialogue concepts and principles; Open Dialogue contributions; Challenges for Open Dialogue implementation in other countries, realities and contexts.
\end{abstract}

Key words Crisis intervention, Family, Social support, Mental health, Open dialogue
Resumo O Método Diálogo Aberto foi desenvolvido na Finlândia para atender crises psíquicas graves utilizando diálogo e inclusão da rede social. Este artigo pretende, através de uma revisão da literatura sobre o Método do Diálogo Aberto, identificar seus princípios e contribuições para processos de desisntitucionalização. Método: As bases utilizadas neste artigo de revisão foram: PubMed (365), PsycInfo (134) e Lilacs (nehuma publicação encontrada), além de 2 livros, incluídos por referência cruzada. Foram selecionadas 34 publicações que atendiam ao objetivo proposto. A busca foi realizada em outubro de 2015. Os descritores selecionados foram: open dialogue, crisis, first episode psycosis, schizophrenia, terapy family, need adapted approach. Resultados: Foram encontrados 3 artigos de revisão, 5 estudos teóricos, 21 estudos qualitativos e 5 estudos quantitativos. Destes, 2 foram escritos em italiano, $1 \mathrm{em}$ francês e 31 em inglês. Com relação ao país de origem dos autores temos: Noruega, Estados Unidos, Finlândia, Austrália, Reino Unido, Bélgica, Canadá e Polônia. As produções foram agrupadas para análise em: Concepções e princípios do Diálogo Aberto; Contribuições do diálogo Aberto; Desafios para implementação do Diálogo Aberto em outros países, realidades e contextos.

Palavras-chave Intervenção em crises, Família, Suporte social, Saúde mental, Diálogo aberto 


\section{Introdução}

O Método Diálogo Aberto foi desenvolvido a partir dos anos de 1980 no oeste da Lapônia, Finlândia, por Jaakko Seikkula e sua equipe, para atender a crise psicótica através de uma intervenção nas primeiras 24 horas, preferencialmente no domicílio do paciente, em uma reunião terapêutica com profissionais, paciente, família e membros significativos da rede social, tendo como o eixo estruturante o diálogo ${ }^{1,2}$.

A prática terapêutica na Finlândia já fazia parte da saúde pública desde os anos de 1960 com o trabalho do professor Yrjö Alanen a partir da psicoterapia individual psicodinâmica, que desenvolveu o modelo "Need-Adapted approach", que focalizava a intervenção precoce na esquizofrenia, a importância do tratamento responder à necessidade de cada paciente e sua família, o trabalho em equipe multidisciplinar, a tomada de decisões compartilhadas nas reuniões de tratamento e o diálogo. O Método do Diálogo Aberto é uma modificação originada nesta abordagem, que vai se aprimorar a partir do início dos anos de 1980 na Finlândia, que foi inspirado na visão sistêmica de rede social, focalizando a abertura do diálogo $0^{2,3}$.

O interesse pelo Método do Diálogo Aberto no mundo cresceu a partir do estudo de resultados sobre o mesmo, do forte questionamento sobre a predominância de um modelo de tratamento centrado nos psicofármacos e suas consequências. $\mathrm{O}$ interesse cresceu também com a divulgação feita por pesquisadores da Noruega, Estados Unidos, Bélgica, Austrália, Reino Unido, Polônia, Canadá, através do relato da experiência positiva vivenciada por aqueles que acompanharam a equipe da Lapônia e do relato de pesquisadores que desenvolveram produções científicas sobre o método ${ }^{4-21}$.

Alguns estudos de avaliação de resultados da aplicação do Método Diálogo Aberto ${ }^{22-26}$ e de revisões de literatura ${ }^{11-13}$ também valorizam este enfoque e destacam a eficácia do tratamento com o Diálogo Aberto no contexto da Lapônia. O estudo mais recente ${ }^{22}$ relacionando à estabilidade de pessoas tratadas com o Diálogo Aberto engloba indivíduos em primeira crise psicótica, em três períodos, de 2 anos cada, compreendidos entre 1992 e 2005 (1992-1993, n=34; 1994-1997, n=46; 2003-2005, n=18). Foi observado que o uso de neurolépticos de modo continuado não se fez necessário em $85 \%$ dos casos no primeiro período, $89 \%$ no segundo período e $72 \%$ no terceiro período. Em média, $88 \%$ das pessoas voltaram a estudar ou trabalhar em tempo integral ao longo dos três períodos ${ }^{22}$. Estes dados sugerem que a ajuda imediata, a inserção da rede social no tratamento, a polifonia das vozes, o diálogo e a tolerância à incerteza contribuem para o acolhimento da experiência dessas pessoas. Os resultados endossam a relevância das práticas de tratamento com o Diálogo Aberto e de seu estudo para o nosso contexto.

O interesse pelo método do Dialogo Aberto cresceu em razão da difusão da consciência acerca das características iatrogênicas, sobretudo a médio e longo prazo, do consumo de psicofármacos. Em 2010, Robert Whitaker ${ }^{27}$ lançou nos Estados Unidos o livro Anatomy of an epidemic: magic bullets, psychiatric drugs, and the astonishing rise of mental illness in America, que recebeu premiação como jornalismo investigativo e se tornou um best seller. No livro, o autor denuncia que o uso intenso e indiscriminado de psicofármacos naquele país trouxe graves consequências para a saúde, com a perda de anos de vida das pessoas e, para o Estado, acarretou um importante aumento no número de pessoas dependentes de auxílio por incapacidade. Nos capítulos finais do livro, entre as experiências exitosas que se propõem a trabalhar reduzindo o consumo de neurolépticos, o autor cita o Diálogo Aberto, apoiado em alguns estudos de avaliação e conta sua experiência de acompanhar a equipe de Seikkula nas reuniões de tratamento, dando destaque para a eficácia do método e instigando o questionamento acerca de sua replicabilidade ${ }^{27}$.

Neste sentido, este artigo de revisão se propõe a apresentar os princípios do Diálogo Aberto e suas principais contribuições para processos de desinstitucionalização do usuário/paciente com sofrimento psíquico, visando responder à seguinte questão: Quais os princípios orientadores das práticas de Diálogo Aberto que podem contribuir para potencializar o cuidado de saúde mental comunitário nos processos de desinstitucionalização em outros contextos?

Objetivo: Identificar concepções, princípios e práticas de Diálogo Aberto que possam contribuir para processos de desinstitucionalização.

\section{Metodologia}

Este consiste num artigo de revisão de literatura. A busca ocorreu em outubro de 2015 e rastreou estudos publicados sobre a abordagem do Diálogo Aberto.

As bases de dados utilizadas foram PubMed (Publish Medline), PscycInfo/APA (American Psychological Association) e Lilacs (Literatura 
Latino-Americana e do Caribe em Ciências da Saúde). O descritor principal utilizado para a busca foi open dialogue (utilizado individualmente e seguido do operador booleano AND e dos descritores que seguem), crisis, first episode psycosis, schizophrenia, therapy family, need adapted. Os filtros considerados nas buscas foram os estudos publicados em língua portuguesa, espanhola, italiana, francesa e inglesa.

Os critérios de inclusão foram: estudos teóricos, de revisão e de pesquisa quantitativos e qualitativos que tratassem do Diálogo Aberto, de seus princípios, concepções, abordagem, experiência, método, tratamento e de seus resultados. Os critérios de exclusão foram: estudos fora da temática, com foco nos transtornos psiquiátricos e em outras abordagens e tratamentos psicoterapêuticos que não o Diálogo Aberto; estudos publicados em finlandês, chinês e japonês.

Os aspectos éticos pertinentes a autorias e citações encontram-se atendidos e respeitados no artigo.

\section{Resultados}

Um total de 501 artigos foram rastreados através da busca nas bases de dados, sendo encontrados 365 na PubMed, 134 na PscycInfo, nenhum estudo na Lilacs. Foram incluídos também 2 livros de autoria de Jaakko Seikkula por referência cruzada. Dos artigos encontrados, 423 foram descartados por encontrarem-se fora da temática, alguns tratavam da esquizofrenia, ou do tratamento da primeira crise em pessoas com diagnóstico de psicose ou, ainda, da terapia familiar utilizando-se de outros métodos e abordagens. Outros 23 estudos foram descartados por serem duplicados, restando assim 55 textos que foram lidos na íntegra. Destes, 21 foram descartados por não abordarem diretamente o tema do Diálogo Aberto. Apesar de discutirem a importância do diálogo para a comunicação terapêutica, não se utilizavam dos princípios, bases epistemológicas e teóricas que delinearam este escopo teórico -prático que se constituiu a partir da experiência finlandesa. Assim, restaram 34 estudos que foram analisados e discutidos nesta revisão.

Das 34 produções científicas, 3 eram artigos de revisão, 5 estudos teóricos, 21 estudos qualitativos e 5 estudos quantitativos. Com relação à língua, 2 eram escritos em italiano, 1 em francês e 31 em inglês. Em 21 artigos e 2 livros, Jaakko Seikkula é um dos autores. Com relação ao país de origem dos autores, temos: Noruega, Estados
Unidos, Finlândia, Austrália, Reino Unido, Bélgica, Canadá e Polônia. Com relação ao período em que foram publicados, onze artigos são do período entre 2001-2005, cinco entre 2006-2010, enquanto que dezesseis artigos e os dois livros foram publicados a partir de 2011 .

\section{Discussão}

O material selecionado foi agrupado para análise em temas, que foram definidos a priori, a partir dos objetivos propostos. Os temas são:

- $\quad$ Concepções e princípios do Diálogo Aberto: São 5 estudos teóricos ${ }^{2,15,18,28,29}$ que abordam os fundamentos do método (Quadro 1);

- Contribuições do Diálogo Aberto para a melhoria da condição de saúde mental e inserção social da pessoa: 5 pesquisas quantitativas ${ }^{22-26} \mathrm{e}$ $3^{11-13}$ estudos de revisão de literatura demonstram que o tratamento com o Diálogo Aberto diminui as hospitalizações, as recaídas, os sintomas residuais e o uso de neurolépticos pelo usuário/ paciente, aumentando sua inserção do através do estudo e trabalho em tempo integral (Quadro 2);

- Desafios para implementação do Diálogo Aberto em outros países, realidades e contextos: Foram analisados 21 estudos qualitativos $^{1,3-10,14,16,17,19-21,30-35}$ que aprofundam as discussões sobre a aplicação do método em casos simples ou múltiplos e contextos específicos. Esta análise possibilita a reflexão sobre potenciais impasses mediante a exigência de mudanças de concepções, organizações, saberes e práticas de cuidado em saúde mental comunitária no contexto da desinstitucionalização (Quadro 3).

\section{Concepções e princípios do Diálogo Aberto}

Entre os textos analisados, artigos ${ }^{15,18,28}$ e dois livros $^{2,29}$ (Quadro 1) mantiveram um enfoque teórico do Diálogo Aberto e abordaram dados históricos, concepções, princípios e elementoschave elencados enquanto critérios de fidelidade.

Seikkula ${ }^{2}$ apresenta uma linha guia com sete princípios fundamentais do Método do Diálogo Aberto, que são: Ajuda imediata (a organização da primeira reunião de tratamento com o paciente, sua família e sua rede social deve ocorrer dentro de 24 horas após o primeiro contato com o serviço); Perspectiva da rede social do paciente (mobilizar as pessoas próximas ao paciente e envolvidas no problema); Flexibilidade e mobilidade (o plano de tratamento deve estar adequado às necessidades do paciente; as reuniões de 


\begin{tabular}{|c|c|c|c|c|c|}
\hline \multirow{7}{*}{ 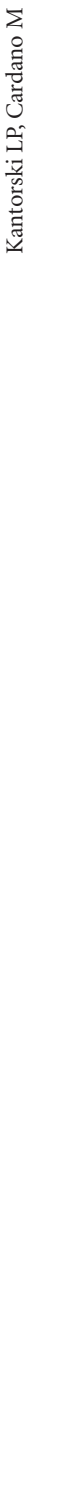 } & \multicolumn{5}{|c|}{ Quadro 1. Estudos revisados sobre concepções e princípios do diálogo aberto. } \\
\hline & $\begin{array}{c}\text { Autor/Local/ } \\
\text { Ano }\end{array}$ & $\begin{array}{c}\text { Tipo de Publicação/ } \\
\text { Periódico }\end{array}$ & Tipo de Estudo & Metodologia & Síntese \\
\hline & $\begin{array}{l}\text { Seikkula², J. } \\
\text { Finlândia. } 2014\end{array}$ & $\begin{array}{l}\text { Livro } \\
\text { Giovani Fioriti } \\
\text { Editore/Roma. Itália. }\end{array}$ & $\begin{array}{l}\text { Livro técnico } \\
\text { que trata do } \\
\text { Diálogo Aberto }\end{array}$ & $\begin{array}{l}\text { Livro técnico que } \\
\text { trata de dados histó- } \\
\text { ricos, conceitos, deta- } \\
\text { lhamento do método } \\
\text { e exemplifica com ca- } \\
\text { sos o Diálogo Aberto } \\
\text { e sua aplicação. }\end{array}$ & $\begin{array}{l}\text { O autor reúne um conjunto de tex- } \\
\text { tos de fundamentação teórica sobre } \\
\text { o Método do Diálogo Aberto, sobre } \\
\text { a natureza do diálogo, seu apoio nas } \\
\text { teorias de Vygotsky e Bakhtin; res- } \\
\text { gata ainda estudos de resultados da } \\
\text { aplicação do método que demons- } \\
\text { tram sua eficácia. }\end{array}$ \\
\hline & $\begin{array}{l}\text { Kłapcinski }^{15}, \mathrm{M} . \\
\text { Wojtynska,R; } \\
\text { Rymaszewska, J. } \\
\text { Polônia. } 2015 .\end{array}$ & $\begin{array}{l}\text { Artigo - ensaio } \\
\text { teórico } \\
\text { Journal of } \\
\text { Schizophrenia } \\
\text { Research. }\end{array}$ & Estudo teórico & $\begin{array}{l}\text { Discussão teórica so- } \\
\text { bre as bases teóricas } \\
\text { e evidências do Di- } \\
\text { álogo Aberto como } \\
\text { abordagem na crise } \\
\text { psicótica. }\end{array}$ & $\begin{array}{l}\text { Apresenta o diálogo aberto enquan- } \\
\text { to abordagem alternativa ao uso de } \\
\text { neurolépticos ou complementar ao } \\
\text { tratamento usual psicossocial. }\end{array}$ \\
\hline & $\begin{array}{l}\text { Olson }^{18}, \mathrm{M} . \\
\text { Seikkula,J., } \\
\text { Ziedonis, D. } \\
\\
\text { Estados Unidos } \\
\text { Finlândia. } 2014 .\end{array}$ & $\begin{array}{l}\text { Artigo - ensaio } \\
\text { teórico } \\
\text { Disponível Home } \\
\text { Page }^{*}\end{array}$ & $\begin{array}{l}\text { Estudo teórico } \\
\text { (define } 12 \\
\text { elementos do } \\
\text { Diálogo Aberto) }\end{array}$ & $\begin{array}{l}\text { Discussão teórica a } \\
\text { partir de elementos } \\
\text { da prática do Diálogo } \\
\text { Aberto, utiliza-se de } \\
\text { exemplos de casos clí- } \\
\text { nicos para elaboração } \\
\text { teórica. }\end{array}$ & $\begin{array}{l}\text { Este artigo centrou-se na definição } \\
\text { da prática dialógica, identificando e } \\
\text { descrevendo doze elementos-chave } \\
\text { desta prática. } \\
\text { *http://umassmed.edu/psychiatry/ } \\
\text { globalinitiatives/opendialogue/ }\end{array}$ \\
\hline & $\begin{array}{l}\text { Seikkula }^{28}, \mathrm{~J} . \\
\text { Finlândia. } 2002 .\end{array}$ & $\begin{array}{l}\text { Artigo - ensaio } \\
\text { teórico }\end{array}$ & Estudo teórico & $\begin{array}{l}\text { Discussão teórica so- } \\
\text { bre as bases da prática } \\
\text { dialógica a partir das } \\
\text { necessidades do pa- } \\
\text { ciente e família. }\end{array}$ & $\begin{array}{l}\text { Apresenta uma argumentação teó- } \\
\text { rica sobre o diálogo como foco da } \\
\text { terapia nas reuniões conjuntas, com } \\
\text { paciente, família, rede. Discussão } \\
\text { sobre o monólogo como a natureza } \\
\text { do núcleo de crise. }\end{array}$ \\
\hline & $\begin{array}{l}\text { Arnkil }{ }^{29}, \text { TE. } \\
\text { Seikkula, J. } \\
\text { Finlândia. } 2012 .\end{array}$ & $\begin{array}{l}\text { Livro } \\
\text { Erickson, Trento. } \\
\text { Itália }\end{array}$ & $\begin{array}{l}\text { Livro técnico - } \\
\text { trata do método } \\
\text { dialógico no } \\
\text { trabalho de rede }\end{array}$ & $\begin{array}{l}\text { Livro técnico que ex- } \\
\text { plora as bases teóricas } \\
\text { da prática dialógica. }\end{array}$ & $\begin{array}{l}\text { Os autores descrevem com base na } \\
\text { sua experiência duas práticas dialó- } \\
\text { gicas, o Diálogo Aberto e o Diálogo } \\
\text { do Futuro (de antecipação ou ante- } \\
\text { cipatório). }\end{array}$ \\
\hline
\end{tabular}

tratamento são organizadas preferencialmente no casa do paciente); Responsabilidade (o profissional que contatado é responsável por organizar a primeira reunião de tratamento, depois é organizada a equipe do caso); Continuidade psicológica (manutenção da continuidade psicológica contando com a colaboração entre o pessoal de vários setores); Tolerância à incerteza (estabelecer um sentimento de confiança para fortalecer o processo de articulação. Em crises psicóticas, um sentido de segurança adequado pressupõe encontros frequentes para restaurar uma sensação de segurança, a fim de tolerar a incerteza relacionada com a situação de crise) e Dialogismo (o foco da reunião é a promoção do diálogo a fim de promover entendimentos e soluções conjuntas). Valorizar a polifonia ${ }^{36}$, a expressão de todas as vozes.
Diálogo Aberto é um sistema de tratamento baseado na comunidade, uma forma de conversa terapêutica que ocorre dentro desse sistema, especificamente dentro da reunião tratamento. Doze elementos-chave da prática dialógica no Diálogo Aberto são elencados enquanto critérios de fidelidade: participação de dois (ou mais) terapeutas nas reuniões de tratamento; envolvimento da família e rede social; usar perguntas abertas; responder às falas do paciente; enfatizar o momento; solicitar múltiplos pontos de vista; usar o foco relacional no diálogo; responder aos problemas dialógicos e comportamentais com um estilo concreto e atento aos significados; enfatizar as palavras usadas pelo paciente e sua história, não os sintomas; a conversa entre profissionais (reflexões) deve ocorrer nas reuniões de tratamento; ser transparente; tolerar a incerteza ${ }^{18}$. 


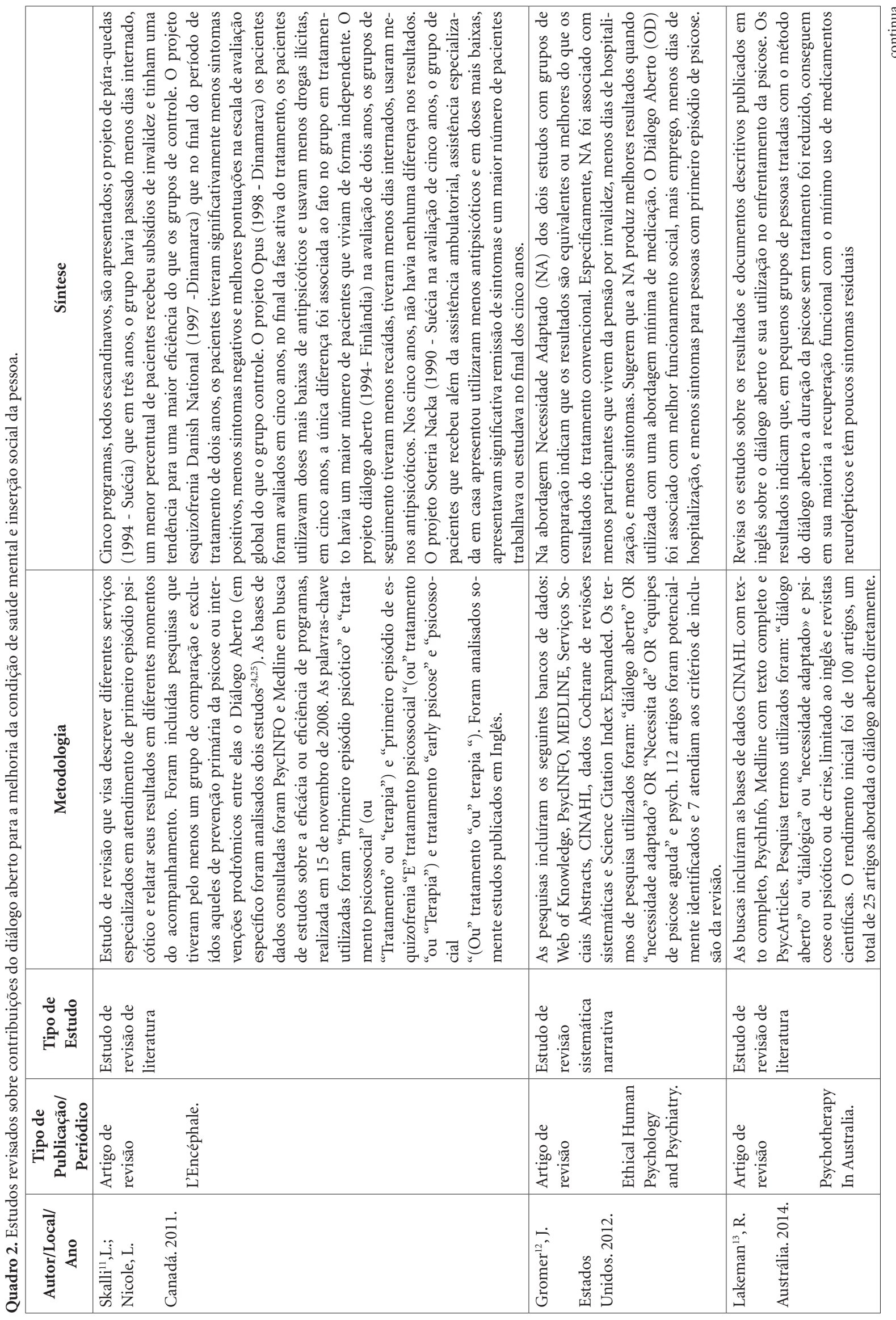




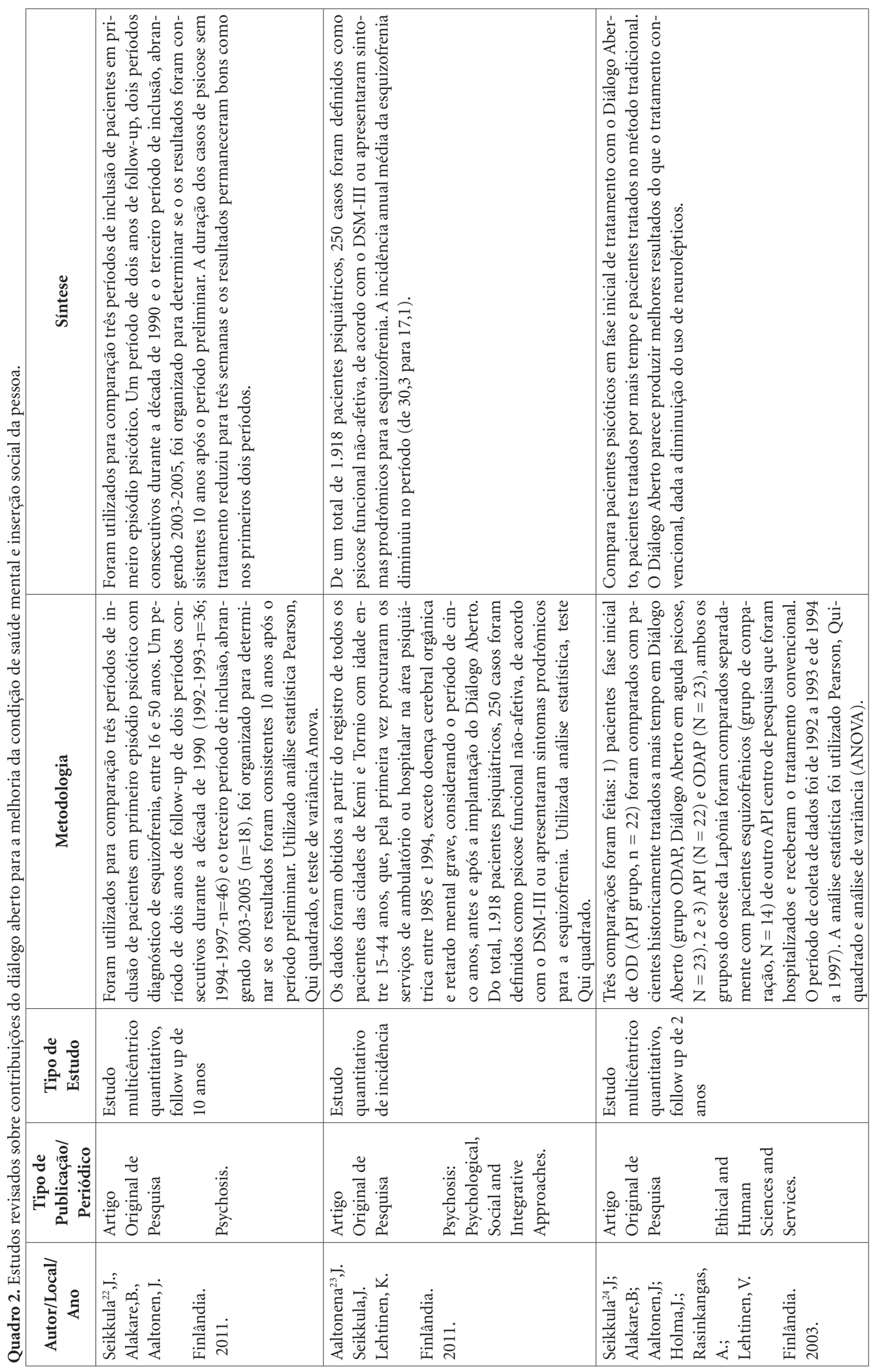




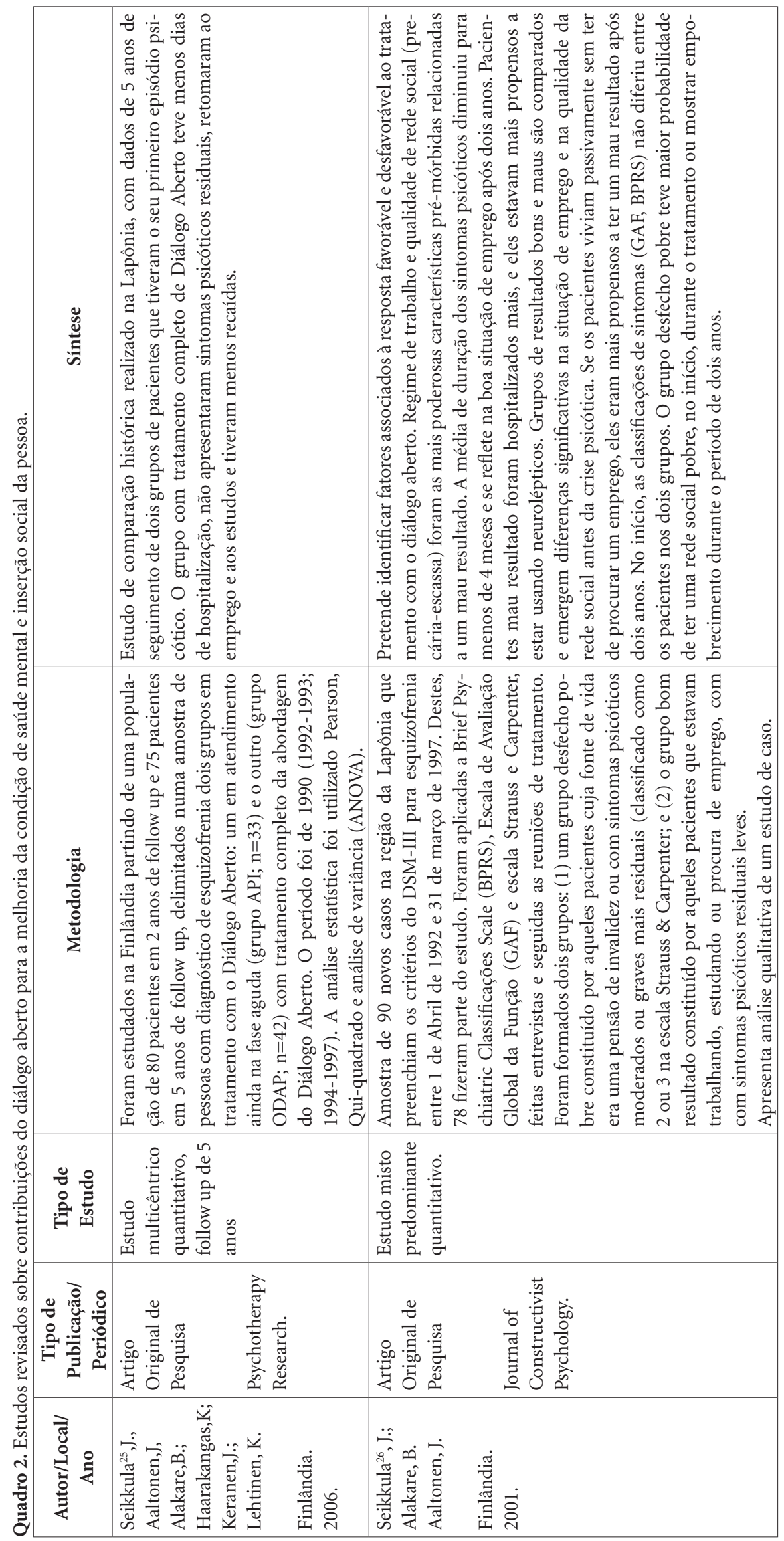




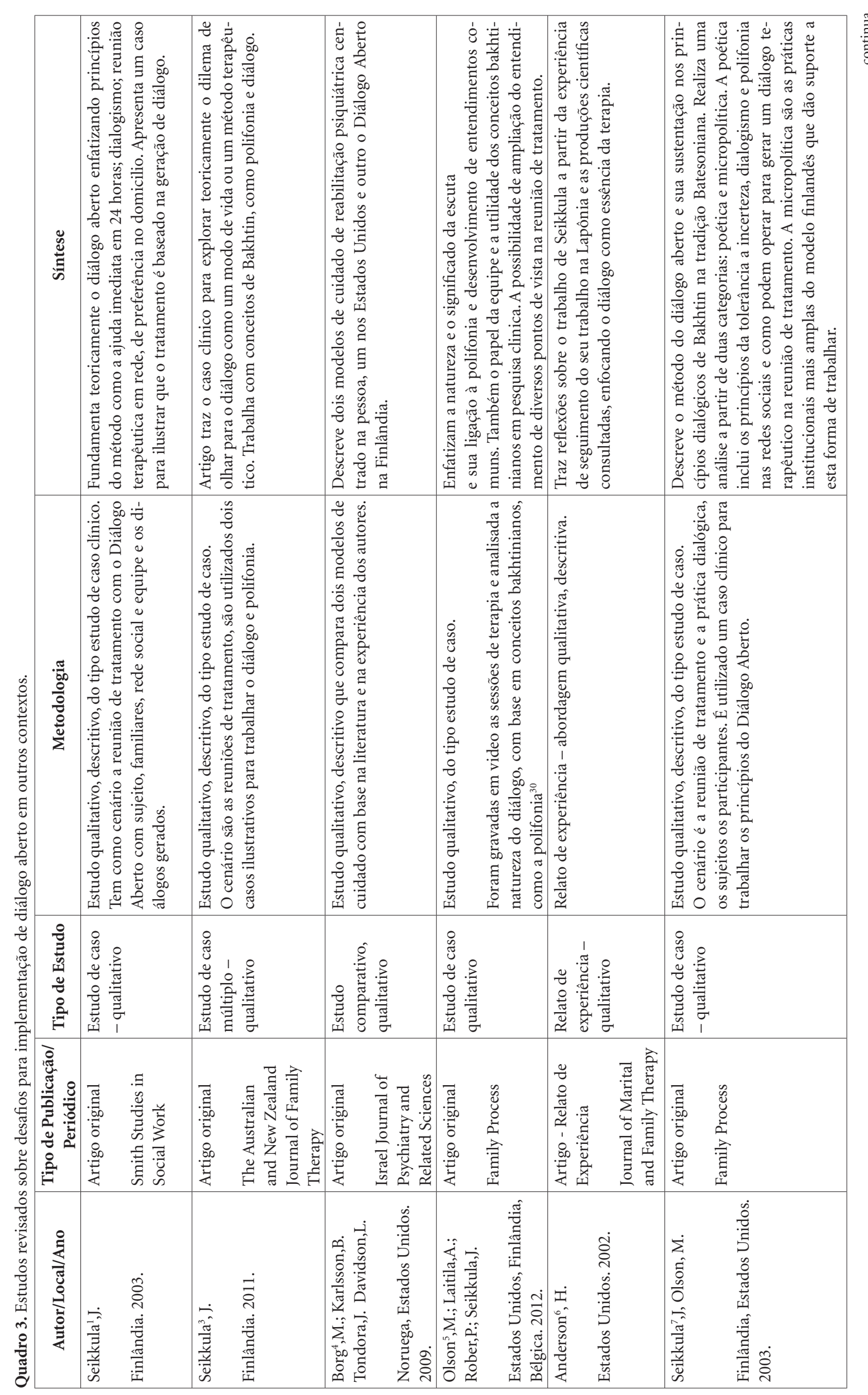




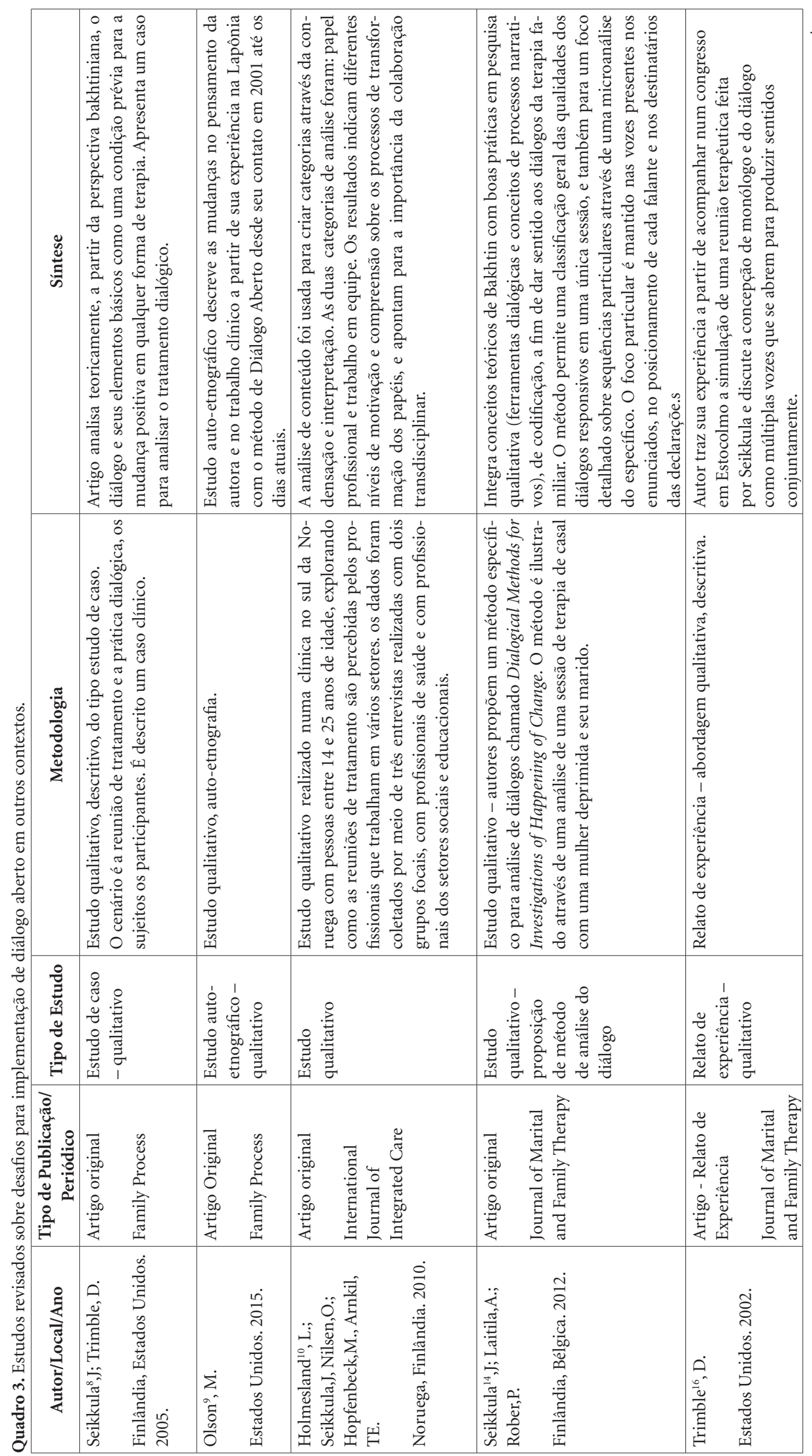




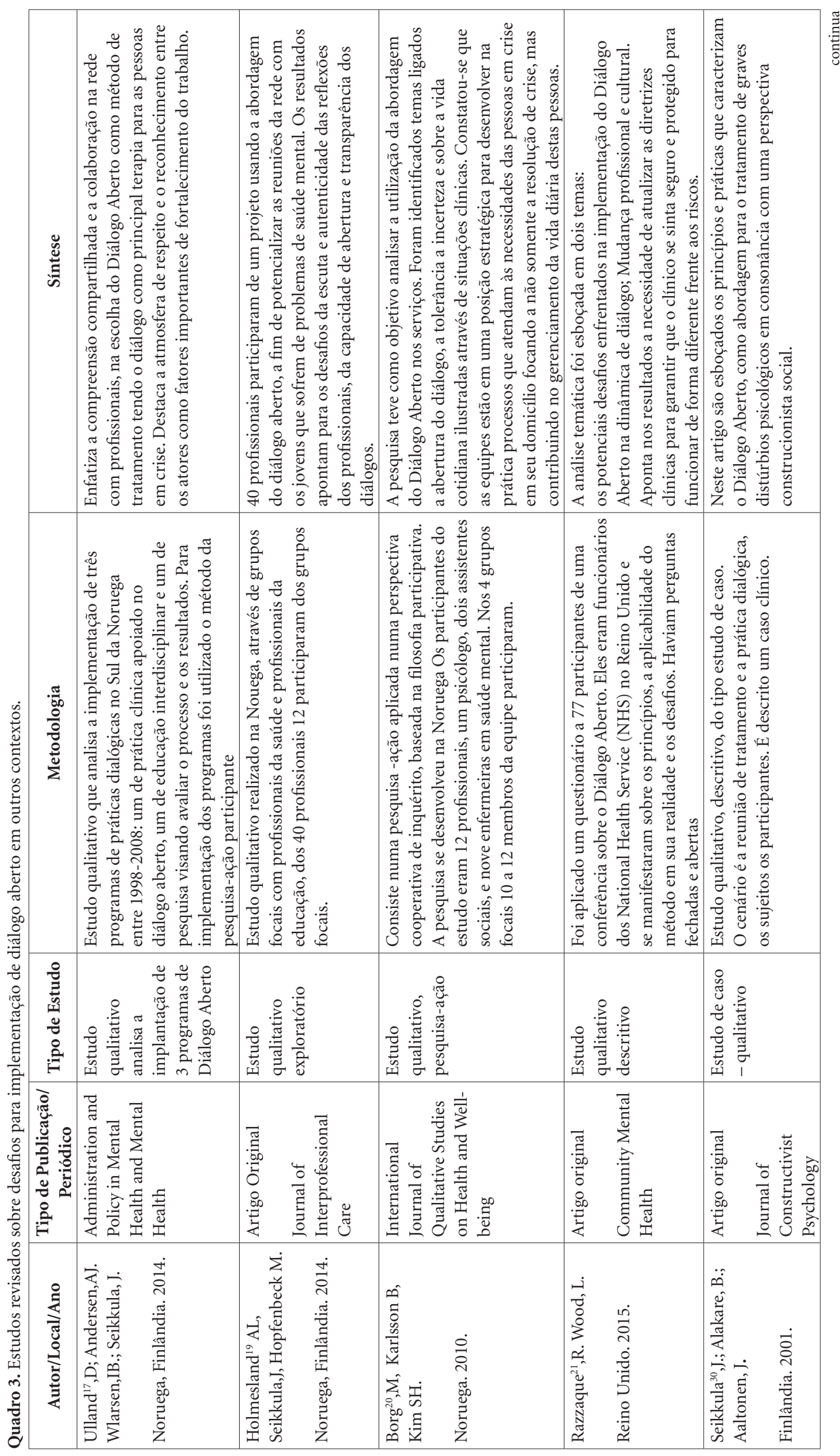




\begin{tabular}{|c|c|c|c|c|c|}
\hline & 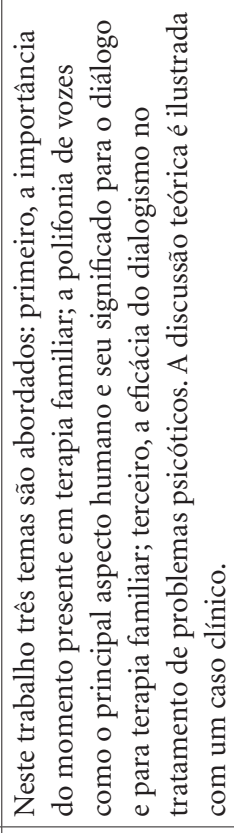 & 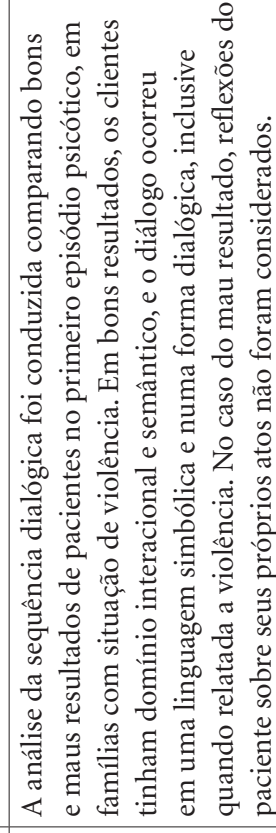 & 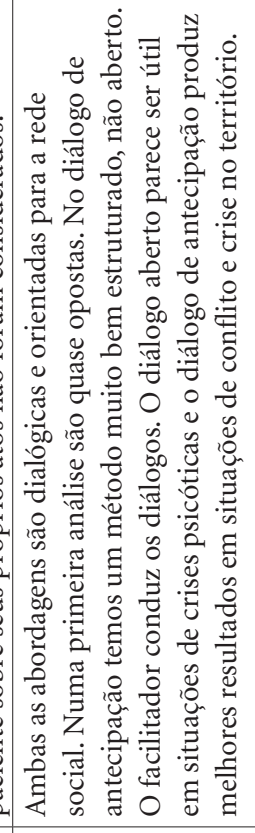 & 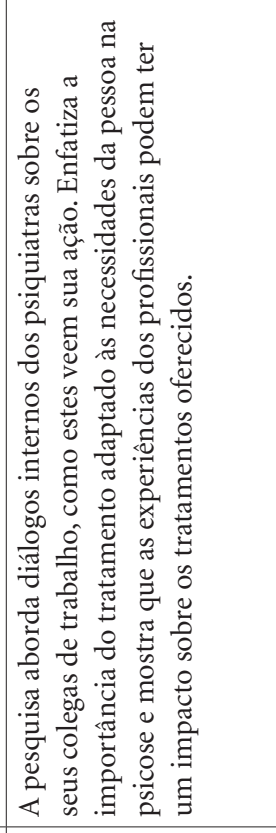 & 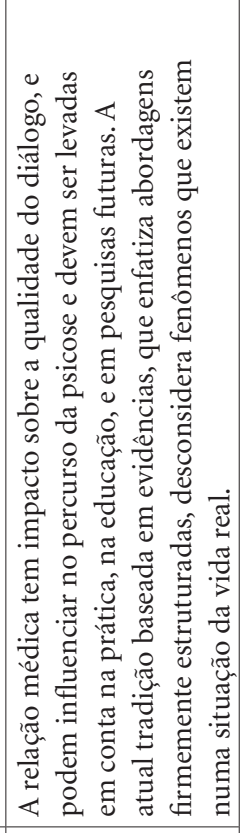 \\
\hline & 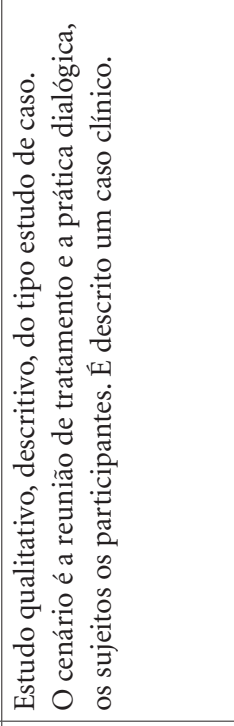 & 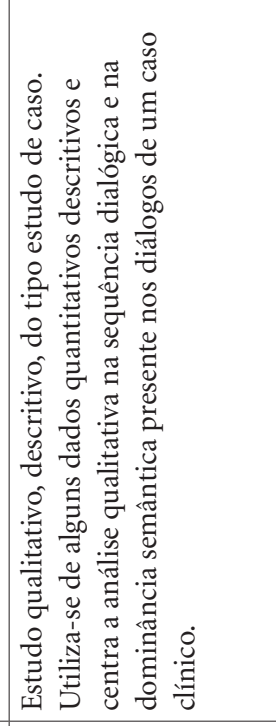 & 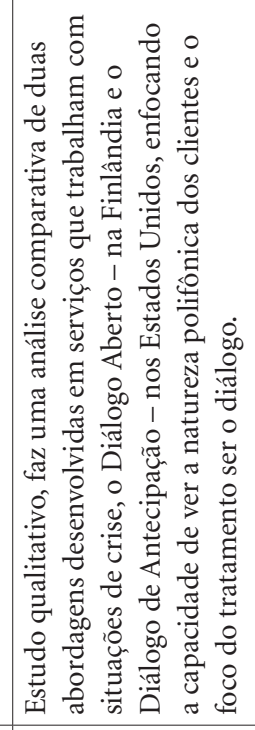 & 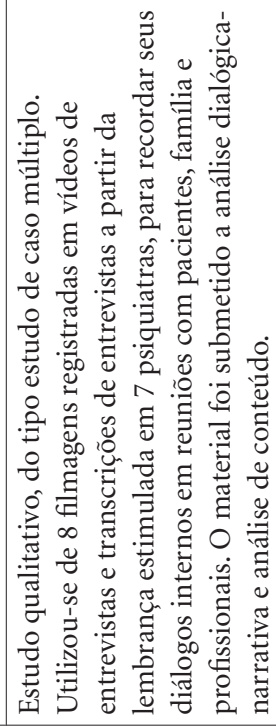 & 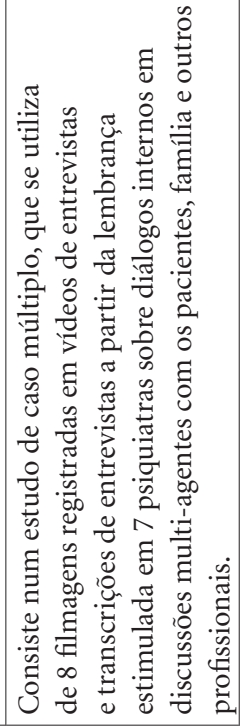 \\
\hline & 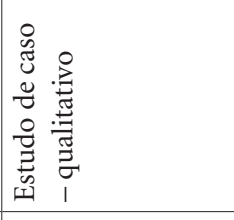 & 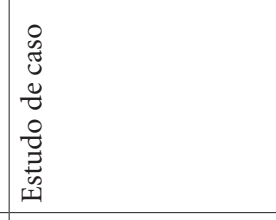 & 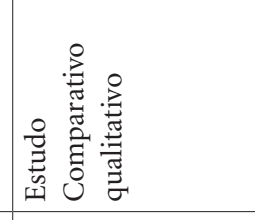 & 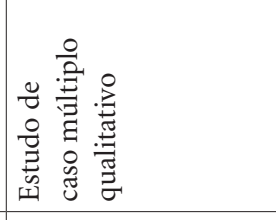 & 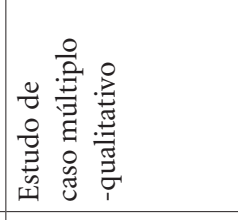 \\
\hline & 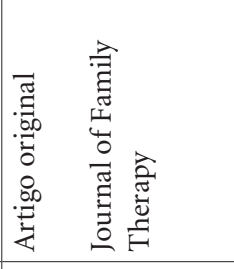 & 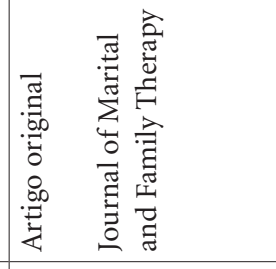 & 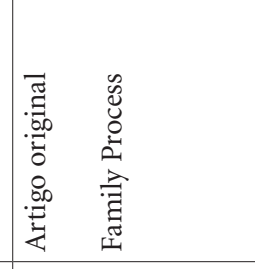 & 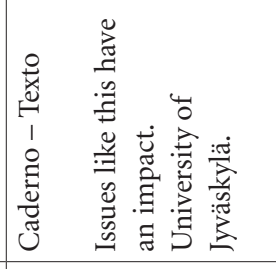 & 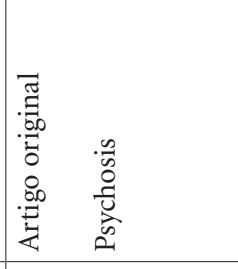 \\
\hline & 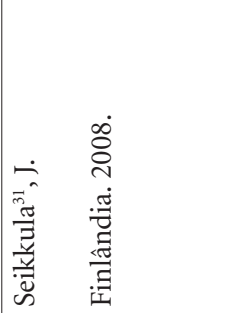 & 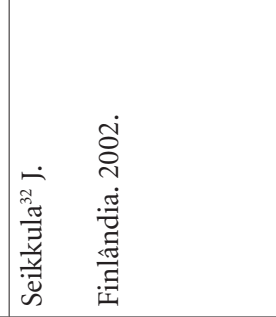 & 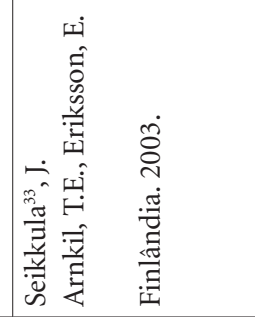 & 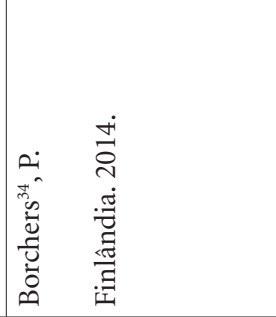 & 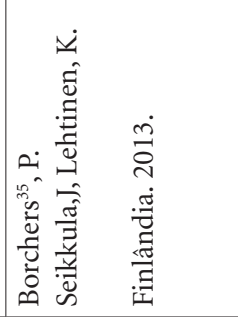 \\
\hline
\end{tabular}


Um importante foco do tratamento com pacientes psicóticos deve ser o rompimento do seu isolamento e concentração no próprio diálogo. Deve-se criar uma linguagem na qual todas as vozes possam ser ouvidas e tanto o paciente como as pessoas próximas dele podem ajudar nesta tarefa. Há dois pré-requisitos para implementar o método: primeiro, trabalhar com equipe. O número ideal são três membros na equipe, caso sejam dois, há o risco de se envolverem nas necessidades da família, mas o terceiro tem a possibilidade de se envolver no diálogo interno e passar a construir uma perspectiva diferente do problema. O segundo pré-requisito consiste em, desde a primeira reunião, envolver as pessoas mais próximas ao paciente, sua família, amigos, aqueles que fazem parte de sua rede social, porque isto também irá garantir o início de uma linguagem comum. A abordagem dialógica visa um processo em que os recursos do potencial do paciente e daqueles próximos a ele começam a desempenhar um papel mais importante na determinação de como proceder no tratamento ${ }^{28}$.

Arnkil e Seikkula ${ }^{29}$ tratam da intervenção precoce e do desafio de ter uma prática dialógica. Apresentam o percurso, a experiência das práticas dialógicas do Diálogo Aberto e do Diálogo do Futuro. Enfatizam princípios como a abertura e a dialogicidade como fundamentais na relação de ajuda a partir do Diálogo Aberto. Eles abordam as qualidades essenciais do diálogo, a importância da polifonia, sua característica multiator (com mais de 2 participantes), sua linha guia, sua difusão e pesquisa.

A contribuição do Diálogo Aberto e sua prática na Lapônia também é evidenciada por autores poloneses ${ }^{15}$, que destacam nos estudos ${ }^{13,25}$ a diminuição do consumo de neurolépticos. No artigo é problematizado o consumo crescente de antipsicóticos, devido à superestimação da eficácia dos neurolépticos e a subestimação do seu potencial prejudicial e enfatizado aspectos culturais, humanistas e comunitários dos serviços na Lapônia e suas intervenções em rede no campo da atenção psicossocial ${ }^{15}$.

O Diálogo Aberto vem a contribuir com os processos desinstitucionalizantes, quando coloca em cena um método sistematizado, conceitualmente organizado e que tem no diálogo, na rede social, na ajuda imediata, na continuidade psicológica, na tolerância à incerteza, na responsabilidade e na flexibilidade o seu cerne. Nos meandros deste detalhamento reside seu potencial, que embora tenha sido estudado e colocado em prática ao longo de mais de vinte anos na Lapô- nia, há tão pouco tempo vem sendo evidenciado no meio acadêmico no cenário mundial.

\section{Contribuições do Diálogo Aberto para a melhoria da condição de saúde mental e inserção social da pessoa}

Dos 5 estudos $^{22-26}$ (Quadro 2) que enfocam os resultados obtidos a partir da utilização do Método do Diálogo Aberto, estes são avaliados através da melhoria da condição de saúde mental e inserção social da pessoa: um deles identifica a incidência de esquizofrenia, um identifica fatores associados à resposta favorável ou desfavorável ao tratamento com o método e três estudos multicêntricos de coorte fazem um follow up em 2, 5 e 10 anos de grupos de pacientes tratados com o Método do Diálogo Aberto em comparação a grupos submetidos a tratamentos convencionais.

No estudo sobre a incidência anual média da esquizofrenia ${ }^{23}$, os dados foram obtidos a partir do registro de todos os pacientes das cidades de Kemi e Tornio (na Finlândia) com idade entre 15-44 anos, que pela primeira vez procuraram os serviços de ambulatório ou hospitalar na área psiquiátrica entre 1985 e 1994, exceto aqueles com doença cerebral orgânica e retardo mental grave, considerando o período de cinco anos, antes e após a implantação do Diálogo Aberto. Do total de 1.918 pacientes psiquiátricos, 250 casos foram definidos como psicose funcional não-afetiva, de acordo com o DSM-III (Diagnostic and Statistical Manual of Mental Disorders) ou apresentaram sintomas prodrômicos para a esquizofrenia. Observou-se que a incidência anual média da esquizofrenia diminuiu no período avaliado (de 30,3 para 17,1), as reações psicóticas breves aumentaram e a incidência de psicoses esquizofreniformes e os sintomas prodrômicos não mudaram. O número de casos novos de esquizofrenia de longa permanência no hospital caiu para zero.

No estudo na Finlândia que identificou fatores associados à resposta favorável e desfavorável ao tratamento com o Diálogo Aberto ${ }^{26}$, todos os 90 novos casos na região que preenchiam os critérios do DSM-III para esquizofrenia, psicose entre $1^{\circ}$ de abril de 1992 e 31 de março de 1997 foram incluídos. Destes, 78 fizeram parte do estudo. Foram aplicadas a Brief Psychiatric Classifications Scale (BPRS), Escala de Avaliação Global da Função (GAF), escala Strauss e Carpenter, entrevistas e reuniões de tratamento. Como resultado, a média de duração dos sintomas psicóticos diminuiu para menos de 4 meses, refletindo em 
uma boa situação de emprego após dois anos. Pacientes com mau resultado foram hospitalizados por maior número de dias e estavam mais propensos a usar neurolépticos (52\%). Cabe destacar que na fase inicial de tratamento os pacientes não diferiram em sintomatologia inicial (classificação BPRS) e função global (GAF), sendo interessante que aqueles com bons resultados após dois anos tenham feito menor uso de medicação $(80 \%)^{26}$.

No estudo multicêntrico quantitativo deste método com um follow up de 2 anos $^{24}$ foram feitas três comparações: 1) pacientes na fase inicial de tratatamento com OD - Open Dialogue (API - Acute Psychosis Integrated Treatment, $\mathrm{n}=22$ ) foram comparados com pacientes historicamente tratados há mais tempo em OD (grupo ODAP - Open Dialogue Acute Psychosis, $\mathrm{n}=23$ ); 2 e 3 ) API $(n=22)$ e ODAP $(n=23)$, ambos os grupos do oeste da Lapônia foram comparados separadamente com pessoas com diagnóstico de esquizofrenia (grupo de comparação, $\mathrm{n}=14$ ) de outro API, que foram hospitalizados e receberam o tratamento convencional. Os pacientes API foram hospitalizados por menos dias; as reuniões foram organizadas com mais frequência com a família, os neurolépticos foram utilizados em menos casos. Os pacientes do grupo ODAP tiveram menos recaídas e menos sintomas psicóticos residuais e sua situação de emprego foi melhor do que no grupo de comparação. Pelo menos uma recidiva ocorreu em 31\% do Grupo API, em 24\% do Grupo ODAP e em 71\% do Grupo de Comparação. A diferença foi significativa entre o grupo API e Grupo de Comparação $(\mathrm{p}<0,05)$. Variáveis como hospitalização $(\mathrm{p}<0,01)$ e neurolépticos $(\mathrm{p}$ $<0,001)$ foram mais frequentemente utilizadas no Grupo de Comparação, no qual 100\% utilizaram neurolépticos na fase inicial contra 36\% no Grupo API e 34\% do Grupo ODAP. O Diálogo Aberto parece produzir melhores resultados do que o tratamento convencional, dada a diminuição do uso de neurolépticos após o tratamento (depois de 2 anos, 71\% do Grupo de Comparação (tratamento convencional) fêz uso de neurolépticos, contra 22\% do Grupo de API e 17\% do Grupo ODAP) $)^{24}$.

No estudo realizado na Lapônia, com dados de $5 \operatorname{anos}^{25}$ de seguimento de dois grupos de pacientes que tiveram o seu primeiro episódio psicótico, foram comparados dois grupos: um em fase inicial (grupo API, $n=33$ ) e um durante o tratamento (grupo ODAP, $\mathrm{n}=42$ ), com completo desenvolvimento da abordagem do Diálogo Aberto. No grupo ODAP, a duração média da psicose não tratada diminuiu para 3,3 meses. $\mathrm{O}$ grupo ODAP teve menos dias de hospitalização e menos encontros familiares. No grupo ODAP, $82 \%$ dos pacientes não tinham sintomas psicóticos residuais, $86 \%$ retomaram os seus estudos ou empregos em tempo integral e 14\% recebiam pensões por incapacidade; $17 \%$ recaíram durante os primeiros 2 anos e 19\% durante os 3 anos seguintes e $29 \%$ usavam medicação neuroléptica durante alguma fase do tratamento.

No estudo multicêntrico quantitativo, follow up de 10 anos $^{22}$, foram utilizados para comparação três períodos de inclusão de pacientes em primeiro episódio psicótico, que foram organizados para determinar se os resultados eram consistentes 10 anos após o início do tratamento com o Diálogo Aberto. O estudo englobou pessoas entre 16 e 50 anos, coerência diagnóstica de $78 \%$ para esquizofrenia (Kappa $=453, \mathrm{p}=002$ ), em três períodos, de 2 anos cada, compreendidos entre 1992 e 2005 (1992-1993, $\mathrm{n}=34$; 1994-1997, $\mathrm{n}=46 ; 2003-2005, \mathrm{n}=18)$ confrontando os grupos, com a análise estatística através do teste de Pearson, Chi quadrado, ANOVA. Durante a década de 1990 (1992-3 e 1994-7), verificou-se que $81 \%$ dos pacientes não apresentaram qualquer sintoma residual psicótico e que $84 \%$ voltaram integralmente para o emprego ou estudo. Apenas 33\% dos pacientes utilizaram medicamentos neurolépticos. No período de 2003-2005, surgiram menor número de casos de esquizofrenia e a idade média dos pacientes psicóticos foi significativamente menor. A duração dos casos de psicose sem tratamento foi reduzida para três semanas e os resultados permaneceram bons, como nos primeiros dois períodos ${ }^{22}$.

Os resultados do tratamento da crise psicótica com o Diálogo Aberto e a eficácia do método foram exaustivamente analisados por três estudos de revisão de literatura ${ }^{11-13}$ (Quadro 2). O primeiro artigo de revisão ${ }^{11}$ descreve diferentes serviços especializados em atendimento de primeiro episódio psicótico e seus resultados em diferentes momentos do acompanhamento. Cinco programas, todos escandinavos, são apresentados: o projeto de paraquedas (1994 - Suécia), o projeto esquizofrenia Danish National (1997 - Dinamarca), o projeto Opus (1998 - Dinamarca), o projeto Soteria Nacka (1990 - Suécia) e o projeto Diálogo Aberto (1994- Finlândia). Com relação ao Diálogo Aberto, a revisão de literatura de Skalli e Nicole ${ }^{11}$, assim como as de Gromer ${ }^{12}$ e Lakeman $^{13}$, fazem um resgate criterioso dos estudos da equipe de Seikkula, no sentido de dar visibilidade às avaliações de eficácia do tratamento, mesmo considerando que sua aplicação tem se 
dado num território bastante delimitado e com características culturais específicas, como o oeste da Lapônia.

\section{Desafios para implementação do Diálogo Aberto em outros contextos}

A identificação de desafios para implementar e/ou replicar o Método do Diálogo Aberto em outros países, realidades e contextos, segue analisada neste artigo a partir dos 21 estudos qualitativos $^{1,3-10,14,16,17,19-21,30-35}$ (Quadro 3) selecionados para esta revisão. Esta opção se deve ao fato de que os estudos qualitativos aprofundam as discussões sobre a aplicação do método em estudos de casos simples ou múltiplos em contextos específicos. Isto possibilita a reflexão sobre potenciais impasses mediante às exigências de mudanças de concepções, organizações, saberes e práticas de cuidado em saúde mental comunitária no contexto da desinstitucionalização.

Alguns artigos ${ }^{1,3-8,10,14,16,19,30-32}$ abordam fortemente o diálogo como uma terapia e não somente como uma ferramenta, ou um recurso, um instrumento. Eles destacam que o processo de escuta é parte integrante da experiência transformadora. Com a escuta, o terapeuta pode evocar novas vozes, criando movimento e novas trajetórias conjuntas ${ }^{5}$. A terapia dialógica e seus componentes são apresentados como o compartilhamento emocional da experiência, a criação de uma nova linguagem compartilhada e de sentimentos de amor como pontos de sintonia emocional gerados na conversa, capazes de sinalizar momentos de mudança terapêutica ${ }^{10}$. A abordagem do Diálogo Aberto se caracteriza pelo estabelecimento de uma consistente equipe de tratamento, que participa de um diálogo respeitoso e deliberativo com o paciente e a família; dá ênfase a reuniões frequentes durante o período de crise inicial e transparência em todas as decisões de tratamento, que devem ser tomadas na presença do paciente e da família ${ }^{30}$. O diálogo é apresentado como terapia e não somente como comunicação. O Diálogo Aberto no interior das reuniões conjuntas é marcado pela polifonia de vozes interiores e exteriores e é compartilhado com o paciente, a família, os profissionais e a rede social. O foco durante as reuniões de tratamento com o paciente e as famílias são as redes sociais e o diálogo ${ }^{31}$.

Consideramos, a partir das leituras revisadas, que tomar a centralidade do diálogo consiste num importante desafio para replicabilidade do método, pois implica em transformações das práticas atualmente bastante focadas nos neurolépticos e voltá-las para a palavra e para a relação. Implica em dispor de uma estrutura organizacional com pessoal com formação adequada em abordagem dialógica, sistêmica, em rede. Implica, também, em sobrepor um modo de pensar dominante, que enxerga no fármaco e na supressão dos sintomas a solução para o conflito e que, por isso, tem menor predisposição para afrontar a crise com a palavra e reconhecer, em cada participante da reunião de tratamento, um papel importante na construção conjunta de possíveis soluções aos problemas apresentados.

Num estudo realizado com grupos focais e observações com profissionais, os autores mostram que os trabalhadores da saúde expressaram preocupações sobre suas capacidades para desenvolver diálogos abertos e transparentes. O que vem a reforçar aspectos desafiadores da prática dialógica ${ }^{19}$.

Trabalhar incluindo a perspectiva da rede social constitui-se num desafio que se soma e se mescla ao diálogo e à polifonia de vozes nas reuniões. Trabalhar com a rede implica num desafio organizacional de mobilizar a rede familiar, de amigos e profissionais em torno do caso. Esta pode ser uma tarefa operacionalmente bastante desafiadora, a depender do modo que opera a instituição, além de sofrer influência de fatores culturais próprios de cada comunidade, dos maiores ou menores laços de solidariedade e tolerância constituídos.

Alguns artigos ${ }^{1,7-9,20,30,32,33}$, ao tratarem do princípio "perspectiva da rede social", enfatizam que na abordagem do Diálogo Aberto, quando uma pessoa ou família em perigo pede a ajuda de um serviço de saúde mental, uma equipe é mobilizada para se reunir com a família e membros interessados da rede social. Nas reuniões de tratamento, a equipe solicita contribuições de cada membro da rede, especialmente o paciente que está em crise psicótica aguda. Todas as falas são ouvidas e estados emocionais intensos são experimentados nas reuniões. Os autores destacam a importância de ampliar as possibilidades de dar sentido às experiências, de utilizar a linguagem da família. Afirmam que, à medida que a rede original incorpora a equipe em sua composição, novos significados emergem quando uma nova linguagem é compartilhada entre a equipe e a rede social. O processo de mudança nas reuniões de tratamento é sutil, promovendo a livre expressão da emoção e da palavra e contribuido para que as redes descubram o que precisam para passar pelas situações difíceis, angustiantes e seguir 
em frente. Certas experiências marcam pontos de transformação no processo de tratamento e incluem fortes sentimentos coletivos de partilha e pertencimento, expressões de confiança emergentes, expressões de emoção; sentimentos de alívio e de tensão ${ }^{7}$.

A inclusão da rede social incorporou-se culturalmente ao sistema de tratamento na Lapônia, como parte do Método do Diálogo Aberto e de um sistema de cuidado em saúde que se enraizou em uma comunidade bem delimitada (com cerca de 72.000 habitantes), em sua maioria de etnia finandesa, de religião protestante e industrializada ${ }^{1}$. Neste contexto, por mais de 20 anos esta prática consolidou um modo de cuidar compartilhado com a comunidade. Neste sentido, a perpectiva de inclusão da rede social no tratamento consiste num desafio organizativo, mas sobretudo cultural, que requer um investimento na mobilização de pessoas a partir de uma lógica de comunidade.

Organizar os serviços de modo que possam dispor de equipes para prestar uma ajuda imediata $^{1,5}$, realizando em 24 horas a primeira reunião de tratamento com o paciente em crise, sua família, pessoas envolvidas no caso, de preferência em domicílio visando diminuir situações de internação, consiste num outro importante desafio na aplicabilidade do Método do Diálogo Aberto. Este desafio de contar com uma estrutura organizativa com um número de pessoas, turnos, horários disponíveis e formação adequada é uma demanda central num primeiro momento, onde a ajuda deve ser imediata e os encontros mais frequentes, mas deve prosseguir depois como garantia da continuidade psicológica do tratamento ao paciente.

O estudo de Borg et al. ${ }^{4}$ descreve dois modelos de cuidado centrados na pessoa, as práticas de cuidado centradas na pessoa planejadas nos Estados Unidos e o modelo finlandês do Diálogo Aberto, destacando seus resultados exitosos por manter o foco na pessoa. Os autores contribuem com esta reflexão evidenciando que o Método do Diálogo Aberto representa um novo modelo abrangente de organização de serviços de saúde mental em uma área geográfica para pessoas com diagnóstico de psicose, com a implementação de métodos clínicos enfatizando estreita colaboração com a pessoa, a família e a rede social. Ressaltam que a estrutura organizacional no oeste da Lapônia conta com uma unidade de internação com 30 leitos hospitalares de cuidados agudos e 5 clínicas ambulatoriais de saúde mental. Possui equipes móveis que tornam acessível ao corpo clínico as necessidades específicas de um determinado paciente. Cerca de 100 profissionais participaram de um processo de formação de três anos em terapia familiar conduzida no trabalho em cooperação com a universidade. Enfatizam que neste contexto da Lapônia algumas escolhas estratégicas foram feitas, a fim de assegurar a continuidade dos cuidados. Nos serviços de internação e clínicas, o Diálogo Aberto é a filosofia de prática e, em cada unidade, equipes móveis para atendimento à crise estão disponíveis quando necessário. O diagnóstico não é um dado específico que define a organização da atenção e o mesmo procedimento é seguido em todas as situações, independente deste ${ }^{4}$.

O termo Diálogo Aberto foi usado pela primeira vez em 1995 para descrever este tratamento, que inclui a família inteira e a rede social do paciente e era centrado em dois aspectos: nas reuniões conjuntas e na construção polifônica, onde todos os membros participam desde o início para gerar o novo entendimento através do diálogo. Estes são os princípios orientadores para todo o sistema de psiquiatria enquanto uma prática dialógia que deve abranger determinada área geográfica ${ }^{3}$. Seikkula ${ }^{3}$ insiste em apontar o desafio de transformar uma prática terapêuttica numa prática que forneceu os princípios básicos para a organização de todo o sistema de tratamento psiquiátrico público, voltada a viabilizar o Diálogo Aberto ${ }^{3}$.

Um outro desafio para a implementação do Diálogo Aberto consiste em tolerar a incerte$\mathrm{za}^{7-8,10,17,20,21,34,35}$. Este princípio é altamente desafiador para os profissionais porque implica em compartilhar responsabilidades, poderes, decisões, em protelar necessidades e em questionar contribuições na situação problema. Seikkula e Olson $^{7}$, num estudo de caso onde foi analisado o diálogo aberto a partir da poética, incluem três princípios: tolerância à incerteza, dialogismo e polifonia nas redes sociais e a micropolítica, enquanto práticas institucionais maiores, que suportem esta forma de trabalhar. A tolerância à incerteza foi objeto de um estudo realizado com profissionais no sul da Noruega, feito por meio de observações e grupos focais. Os resultados indicaram diferentes níveis de motivação e compreensão sobre os processos de transformação do papel profissional para realização de colaboração transdisciplinar ${ }^{10}$.

Além dos recursos humanos e financeiros para implantação do Método do Diálogo Aberto no Reino Unido, outro potencial desafio a ser enfrentado consiste na mudança profissional e cul- 
tural. Os autores reconhecem que os médicos seriam confrontados com uma série de obstáculos relacionados às responsabilidades pessoais significativas. Eles podem não se sentir capazes de assumir trabalhar com o Diálogo Aberto. Sugerem como um passo na implementação do Diálogo Aberto a atualização de diretrizes clínicas de modo a garantir que o médico se sinta seguro e protegido para funcionar de forma diferente. Afirmam que o Diálogo Aberto requer dividir o poder profissional e trabalhar em condição de igualdade com quem utiliza o serviço e sua rede. Os autores reforçam que esta pode ser uma situação ameaçadora para os médicos que foram ensinados e orientados a uma prática especialista, com um poder psiquiátrico inerente reconhecido e atraente para muitos ${ }^{21}$.

Num estudo de caso múltiplo com psiquiatras, a partir de filmagens registradas em vídeos de entrevistas e transcrições de entrevistas enfocando diálogos internos em discussões com os pacientes, com a família e com outros profissionais, é evidenciado que as forças institucionais podem ter um enorme impacto no modo de agir dos psiquiatras, reduzindo sua criatividade profissional ${ }^{34}$.

Em outro estudo de caso múltiplo, há a indicação de que a formação e supervisão de psiquiatras deveria melhorar o seu autoconhecimento, suas habilidades dialógicas, e sua capacidade de tolerar a incerteza nos tipos de relacionamentos complicados que existem dentro da equipe multiprofissional e nos processos que ocorrem durante o tratamento da psicose $\mathrm{e}^{35}$. Ao ser analisada a implementação de programas de práticas dialógicas no Sul da Noruega, entre 1998-2008, é destacado que as práticas dialógicas exigem compreensão compartilhada da abordagem Diálogo Aberto e colaboração entre redes de profissionais e entre os líderes. A cultura da terapia médica tradicional se mostra como obstáculo à colaboração ${ }^{17}$.

No Método do Diálogo Aberto durante uma crise psicótica, um sentido de segurança adequado pressupõe um encontro todos os dias, pelo menos nos primeiros 10-12 dias. Depois, as reuniões podem ser organizadas regularmente de acordo com as necessidades e desejos da família. Isto contribui para a tolerância à incerteza. Normalmente, nenhum contrato terapêutico detalhado é feito na fase de crise, de modo a evitar conclusões e decisões prematuras em relação ao tratamento. Neste sentido, os neurolépticos não são iniciados na primeira reunião; em vez disso, a sua pertinência deve ser discutida em, pelo menos, três reuniões antes da implementação ${ }^{31}$.
Considera-se que a tolerância à incerteza é um desafio importante na implementação e replicabilidade do Método do Diálogo Aberto, porque coloca em questionamento posições hierárquicas na equipe, relações de poder entre profissionais e pacientes e retira a centralidade do psicofármaco como instrumento principal de tratamento, para dar lugar ao diálogo.

\section{Conclusão}

Este artigo de revisão teve como objetivo identificar na literatura os princípios e concepções do Diálogo Aberto. As bases para compreensão do Diálogo Aberto estão na centralidade do diálogo, na polifonia de vozes nas reuniões de tratamento, na inclusão da perspectiva da rede social, na organização dos serviços para prestar uma ajuda imediata, realizando em 24 horas a primeira reunião de tratamento com o paciente em crise, sua família e rede, na tolerância à incerteza, incluindo as questões de não precipitar o uso dos medicamentos neurolépticos, da responsabilidade, da flexibilidade e da continuidade psicológica.

A experiência de mais de 20 anos divulgada especialmente nos estudos de caso qualitativos e nos artigos de pesquisadores de outros países, que fizeram um acompanhamento da experiência na Lapônia e os estudos de pesquisa de avaliação de eficácia do tratamento pelo Diálogo Aberto, contribuem nesta revisão de literatura para endossar a relevância da temática. As evidências produzidas que relacionam o tratamento do Diálogo Aberto à redução do uso de neurolépticos, à redução no número de dias de internação hospitalar, menos sintomas residuais, à maior integração social pelo estudo e trabalho em tempo integral trazidas nesta revisão de literatura são reveladoras da potencialidade do método de tratamento. Para o avanço dos estudos sobre o tema, sugerese outras pesquisas relacionadas às habilidades sociais, autonomia, inserção da pessoa em diferentes tipos de emprego e em diferentes fases e programas escolares, composição e densidade de rede social. Estudos qualitativos que enfoquem aspectos subjetivos do tratamento, das reuniões, da interrupção do uso de psicofármacos, também de aspectos organizativos e culturais envolvidos na implementação do Diálogo Aberto se fazem necessários.

Neste sentido, entende-se ser de fundamental relevância a implementação do Diálogo Aberto e que ele pode potencializar os processos de avanço no campo da desinstitucionalização. As equipes, 
contextos e países empenhados em fazer avançar suas práticas de cuidado em saúde mental na comunidade e no domicílio a partir das bases do diálogo e da rede social podem encontrar no Diálogo Aberto um importante aliado.

\section{Colaboradores}

A autora LP Kantorski trabalhou na concepção, delineamento, análise e interpretação dos dados, na redação do artigo e na aprovação da versão a ser publicada. E o coautor M Cardano trabalhou na concepção, delineamento, análise e interpretação dos dados, na redação do artigo e na aprovação da versão a ser publicada.

\section{Referências}

1. Seikkula J. Open dialogue integrates individual and systemic approaches in serious psychiatric crises. Smith Coll Stud Soc 2003; 73(2):227-245.

2. Seikkula J. Il dialogo aperto: l'approccio finlandese alle gravi crisi psichiatriche. Roma: Giovani Fioriti Editore; 2014.

3. Seikkula J. Becoming dialogical: psychotherapy or a way of life? Aust N Z J Fam Ther 2011; 32(3):179-193.

4. Borg M, Karlsson B, Tondora J, Davidson L. Implementing person-centered care in psychiatric rehabilitation: what does this involve? Isr J Psychiatry Relat Sci 2009; 46(2):84-93.

5. Olson M, Laitila A, Rober P, Seikkula J. The shift from monologue to dialogue in a couple therapy session: dialogical investigation of change from the therapists' point of view. Fam Process 2012; 51(3):420-435.

6. Anderson H. In the space between people: Seikkula's open dialogue approach. J Marital Fam Ther 2002; 28(3):279-281.

7. Seikkula J, Olson ME. The open dialogue approach to acute psychosis: its poetics and micropolitics. Fam Process 2003; 42(3):403-418.

8. Seikkula J, Trimble D. Healing elements of therapeutic conversation: dialogue as an embodiment of love. Fam Process 2005; 44(4):461-475.

9. Olson M. An auto-ethnographic study of "open dialogue": the illumination of snow. Fam Process 2015; 54(4):716-729.

10. Holmesland AL, Seikkula J, Nilsen O, Hopfenbeck M, Arnkil TE. Open dialogues in social networks: professional identity and transdisciplinary collaboration. Int J Integr Care 2010; 10:1-14.

11. Skalli L, Nicole L. Specialised first-episode psychosis services: a systematic review of the literature. Encephale 2011; 37(Supl. 1):66-76.

12. Gromer J. Need-adapted and open-dialogue treatments: empirically supported psychosocial interventions for schizophrenia and other psychotic disorders. Ethical Hum Psychol Psychiatry 2012; 14(3):162-177.

13. Lakeman R. The finnish open dialogue approach to crisis intervention in psychosis: a review. Psychotherapy in Australia 2014; 20(3):26-33.

14. Seikkula J, Laitila A, Rober P. Making sense of multi-actor dialogues in family therapy and network meetings. J Marital Fam Ther 2012; 38(4):667-687.

15. Kłapciński M, Wojtynska R, Rymaszewska J. Open dialogue approach - an alternative to neuroleptics or development of pharmacologically cautious treatment of schizophrenia? J Schizophr Res 2015; 2(2):1013-1014. 
16. Trimble, D. Listening with integrity: the dialogical stance of Jaakko Seikkula. J Marital Fam Ther 2002; 28(3):275-277.

17. Ulland D, Andersen AJW, Larsen IB, Seikkula, J. Generating dialogical practices in mental health: experiences from southern Norway, 1998-2008. Adm Policy Ment Health 2014; (41):410-419.

18. Olson M, Seikkula J, Ziedonis D. The key elements of dialogic practice: in open dialogue: fidelity criteria. Version 1.1: September 2, 2014. Available from: http:// umassmed.edu/psychiatry/globalinitiatives/opendialogue/

19. Holmeslnd AL, Seikkula J, Hopfenbeck M. Inter-agency work in Open Dialogue: the significance of listening and authenticity. J Interprof Care 2014; 28(5):433-439.

20. Borg M, Karlsson B, Kim HS. Double helix of research and practice-developing a practice model for crisis resolution and home treatment through participatory action research. Int J Qual Stud Health Well-being. 2010; 5(4647):1-8.

21. Razzaque R, Wood L. open dialogue and its relevance to the NHS: opinions of NHS staff and service users. Community Ment Health J 2015; 51(8):931-938.

22. Seikkula J, Alakareb B, Aaltonena J. The comprehensive open-dialogue approach in western Lapland II - longterm stability of acute psychosis outcomes in advanced community care. Psychosis 2011; 3(3):192-204.

23. Aaltonen J, Seikkula J, Lehtinenb K. The comprehensive open-dialogue approach in western Lapland I - the incidence of non-affective psychosis and prodromal states. Psychosis 2011; 3(3):179-191.

24. Seikkula J, Alakare B, Aaltonen J, Holma J, Rasinkangas A. Open dialogue approach: treatment principles and preliminary results of a two - year follow-up on first episode schizophrenia. Ethical Hum Sci Serv 2003; 5(3):163-182.

25. Seikkula J, Aaltonen J, Alakare B, Haarakangas K, Keranen J, Lehtinen K. Five-year experience of first-episode non affective psychosis in open-dialogue approach: Treatment principles, follow-up outcomes, and two case studies. Psychother Res 2006; 16(2):214-228.

26. Seikkula J, Alakare B, Aaltonen J. Open dialogue in psychosis II: a comparison of good and poor outcome cases. J Constr Psychol 2001; 14:267-284.
27. Whitaker R. Anatomy of an epidemic: magic bullets, psychiatric drugs, and the astonishing rise of mental illness in America. New York: Crown Publishing Group; 2010.

28. Seikkula J. Monologue is the crisis-dialogue becomes the aim of therapy. J Marital Fam Ther 2002; 28(3):283284.

29. Arnkil TE, Seikkula J. Metodo dialogici nel lavoro di rete: per la psicoterapia di gruppo, il servizio sociale e la didattica. Trento: Erickson; 2012.

30. Seikkula J, Alakare B, Aaltonen J. Open dialogue in psychosis I: an introduction and case illustration. J Constr Psychol 2001; 14(4):247-265.

31. Seikkula J. Inner and outer voices in the present moment of family and network therapy. J Fam Ther 2008; (30):478-491.

32. Seikkula J. Open dialogues with good and poor outcomes for psychotic crises: examples from families with violence. J Marital Fam Ther 2002; 28(3):263-274.

33. Seikkula J, Arnkil TE, Eriksson E. Postmodern society and social networks: open and anticipation dialogues in network meetings. Fam Process 2003; 42(2):185-203.

34. Borchers P. Issues like this have an impact. The need-adapted treatment of psychosis and the psychiatrist's inner dialogue. Jyväskylä: University of Jyväskylä, 2014.

35. Borchers P, Seikkula J, Lehtinen K. Psychiatrists inner dialogues concerning workmates during need adapted treatment of psychosis. Psychosis 2013; 5(1):60-70.

36. Bakhtin M. Problemas da poética de Dostoiévski. Rio de Janeiro: Forense Universitária; 1997.

Artigo apresentado em 19/08/2016

Aprovado em 02/03/2017

Versão final apresentada em 04/03/2017 